\title{
Pharmacological, biochemical and molecular investigations in 6-OHDA induced Parkinson's disease rats on the protection benefits of mangiferin in behavioral, inflammatory and oxidative biomarkers
}

Prafulla Chandra Tiwari ${ }^{1}$, Mayank Jain, Shipra Kartik ${ }^{1}$, Rajendra Nath ${ }^{1}$, Rishi Pal*1

1. Department of Pharmacology \& Therapeutics, King George's Medical University, UP, Lucknow-226003, India

Author Details:

1. Prafulla Chandra Tiwari, Department of Pharmacology \& Therapeutics, King George's Medical University, UP, Lucknow-226003, India. Email: tiwari.prafulla009@ gmail.com

2. Mayank Jain, Department of Pharmacology \& Therapeutics, King George's Medical University, UP, Lucknow-226003, India Email: mayank284@gmail.com

3. Sipra Kartik, Department of Pharmacology \& Therapeutics, King George's Medical University, UP, Lucknow-226003, India Email: kartikshipra@ gmail.com

4. Dr Rajendra Nath, Department of Pharmacology \& Therapeutics, King George's Medical University, UP, Lucknow-226003, India Email: Rajendra.nath79@gmail.com

5. Dr. Rishi Pal, Department of Pharmacology \& Therapeutics, King George's Medical University, UP, Lucknow-226003, India Email: rishipal@kgmcindia.ed

Running Title

Tiwari PC et al. Protective effect of mangiferin in 6-OHDA induced PD rats

Corresponding Author: Dr Rishi Pal, Department of Pharmacology \& Therapeutics, King George's Medical University, UP, Lucknow-226003, India 


\section{Graphical Abstract}

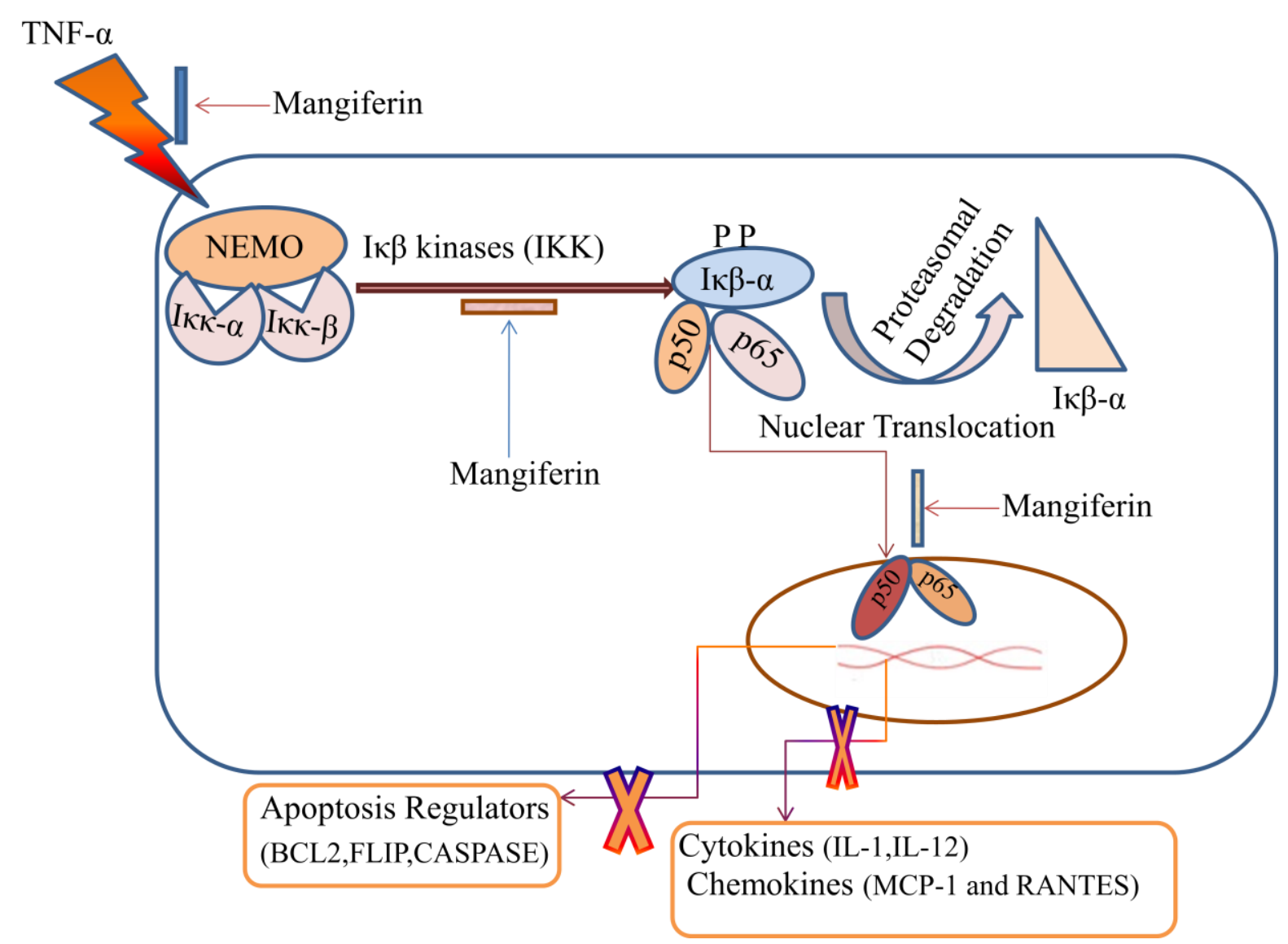

Mangiferin prevents inflammation by inhibiting TNF- $\alpha$ mediated nuclear translocation and activation of NF- $\kappa \mathrm{B}$, which is required for activation of COX and TLRs. Mangiferin, also prevents phosphorylation of NF- $\mathrm{\kappa B}$ by promoting its proteasomal degradation, which further decreases the secretion of inflammatory cytokines such as IL-1, IL-12, Chemokines such as MCP-1 and RANTES. Mangiferin further decreases the activation of caspases and FLIP proteins by inhibiting TNF- $\alpha$, NF-kB and MAPK mediated cell death pathways. 


\begin{abstract}
:
Background: Persistent up regulation of NF- $\mathrm{BB}$ leads to chronic inflammation and subsequent microglial activation and takes neurons towards death by activating death receptor domains and the p53 pathway. Thus, inhibition of NF- $\kappa \mathrm{B}$ may lead to more effective treatment for Parkinson's disease. Therefore, we have used mangiferin, specific inhibitor of $\mathrm{NF}-\kappa \mathrm{B}$ in this study.
\end{abstract}

Method: The study utilized male Wistar rats weighing 200-250 gm ( $\mathrm{n}=8$ in each group). Stereotactic surgery of rats was done to induce 6-OHDA lesioning in rats. On day 42 , rats were subjected to behavioural studies to evaluate effect of mangiferin and their brains were taken out after euthanasia to perform biochemical and molecular studies.

Results: Mangiferin significantly increases locomotor parameters in 6-OHDA lesioned rats. It also decreases activity of Cyclooxygenase enzyme which then leads to decrease concentration of inflammatory cytokines. Microglial inflammation was also substantially reduced by reducing MPO concentration. Oxidative stress burden was also reduced after treatment with mangiferin as indicated by increase in Total Antioxidant Capacity, SOD and Catalase and reduction in concentration of MDA. Treatment with mangiferin also reduces burden of oxidative stress by increasing the activity of NRF2/ARE pathway. Activity of Caspase 3 and 9 was also significantly reduced after treatment with mangiferin. Significant decrease in activity of both Cox 1 and Cox 2 was also observed. Maximum improvement in all parameters was observed in rats treated with grouping of mangiferin $45 \mathrm{mg} \cdot \mathrm{kg}^{-1}$ and levodopa $10 \mathrm{mg} \cdot \mathrm{kg}^{-1}$. Treatment with levodopa alone has no significant effect on biochemical and molecular parameters though it significantly improves behavioural parameters.

Conclusion and Implications: Results of this study suggest that mangiferin has protective effect in hemi-parkinsonian rats by inhibiting NF- $\mathrm{BB}$. Current treatment of Parkinson's disease does not target the underlying problem of the disease. Therefore, combination therapy of mangiferin and levodopa can be helpful in better management of Parkison's.

Keyword: 6-OHDA, NF-кB, Mangiferin, Inflammation, Cox, Caspases 


\section{Introduction}

Parkinson's disease (PD) is a progressive locomotor disorder characterized by death of neurons in the nigrostriatal area of basal ganglia. Bradykinesia, muscular rigidity, rolling tremors in the pill, postural abnormalities and gait issues are some of the clinical features of PD [1],[2],[3],[4].

Though PD is an idiopathic disorder with its etiopathology not fully known, after decades of research, researchers believe that dysregulation of transcription factors controlling inflammation is the key reason behind the advancement of PD and PD like symptoms. Various studies have suggested that the expression of transcription factor NF- $\kappa B$ increases during inflammation. Increased expression of transcription factor NF- $\kappa \mathrm{B}$ then results in downstream activation of Toll like receptors (TLRs) and Interleukin 1 Receptors (IL1R), which then triggers Myd88 gene to recruit Interleukin1 Receptor Activated Kinase 1 (IRAK1) to this receptor signaling complex for phosphorylation. After phosphorylation, IRAK1 form a complex with Tumor necrosis factor Receptor Associated Factor 6 (TRAF6). The IRAK-1 TRAF-6 complex thus formed then activates NF-kB signaling pathway through TAK1/TAB1/TAB2, NEMO/IKK $\beta / \mathrm{IKK} \alpha$ and I $\kappa \mathrm{B} / \mathrm{p} 50 / \mathrm{p} 65$ complexes [5], [6], [7], [8], [9], which then subsequently leads to gene induction of pro-inflammatory cytokines by NF- $\kappa$ B. Thus, increased secretion of NF- $\mathrm{KB}$ mediated pro-inflammatory cytokines such as IL-1 and TNF- $\alpha$ and transcription factors like TLR-4 then result in microglial activation. These activated microglial cells then further aggravate the inflammatory response by secreting TNF- $\alpha$, IL-1 $\beta$ and IL-6. These activated microglial cells then further aggravate the inflammatory response by secreting TNF- $\alpha$, IL-1 $\beta$ and IL-6. Activated microglial cells also produce NO due to increased expression of iNOS in glial cells. Furthermore, activation of the microglia also increases ROS production due to NADPH induction and causes oxidative stress and free radical-induced cell injury [10], [11], [12], [13], [14], [15], [16], [17]. All these factors then further increase the expression of NF- $\kappa \mathrm{B}$, which then regulates apoptosis through the nuclear buildup of RelA. Nuclear translocation of RelA then increases the membrane permeability of mitochondria by chaperon mediated activation of Bax onto the outer membrane of mitochondria and inhibiting the anti-apoptotic protein Bcl-XL [18]. Increased ROS production causes activation of p38/MAPK pathway. Activation of p38/MAPK then triggers NF- $\kappa B$ activation which then activates p53 gene [19]. This ROS mediated activation of p38/MAPK then induces the expression of caspase - 3 and caspase-9 [20, 21] [22], [23], [24], [25], [26], [27], [28], [29], [30], [31], [32]. 
In recent years, research interest in natural compounds has been revivified owning to their slighter toxic effect as compared to chemical compounds. In our study, we have used polyphenolic compound Mangiferin obtained from plants belonging to Anacardiaceae and Gentianaceae family.

Mangiferin subdues the inflammatory reaction primarily by prying with NF- $\kappa \mathrm{B}$ activation, which further aggravates ferocious cycle of inflammation by activating cytokines such as TNF- $\alpha$, IL-1 and IL-4 and signaling pathways such as STATs and TLRs. Mangiferin first and foremost impedes NF- $\kappa \mathrm{B}$ activation as it pickle with NEMO (NF- $\kappa \mathrm{B}$ essential modulator), IKK- $\alpha$ and IIK- $\beta$ complex, which forestall its auxiliary phosphorylation and consequent degradation and translocation of this complex in to nucleus [33],[34],[35],[36]. Mangiferin also has diminutive effects on (a) TNF receptor-associated factor 6 (Traf6) (b) TNF-receptorassociated death domain (TRADD), and the receptor interacting protein (RIP); and (c) macrophage and phagocyte producing property of NO [37],[38].

Thus, owing to its anti-inflammatory and anti-oxidant effect, mangiferin could be useful in pharmacotherapy of PD to rescue the neurons from cell death pathways.

\section{Methodology:}

\section{Animals:}

Male wistar rats (200-250 gm) were used in the study. Rats (n=8/group) were kept in the Institutional Animal Facility of the University under $12 \mathrm{hr}$. light/dark cycles with free access to food \& water. Before starting the study, necessary approval from the Institutional Animal Ethics Committee (IAEC) of King George's Medical University (KGMU), Lucknow was obtained with approval letter No. 84/IAEC/Pharma/2017.

\section{Induction of Parkinson's disease in Rats}

6-OHDA lesions were performed in rats using stereotactic frame. Rats were anesthetized with ketamine-xylazine (ketamine $60 \mathrm{mg} \cdot \mathrm{kg}^{-1}$ and xylazine $7.5 \mathrm{mg} \cdot \mathrm{kg}^{-1}$ ) cocktail before placing them in to stereotactic chamber. Top of rat's head was shaved and cleaned through $70 \%$ ethanol. Stereotactic coordinates for substantia nigra region was then determined using Paxinos and Watson, The Rat Brain in Coordinates[39]. For substantia nigra pars compacta $(\mathrm{SNpc})$ (dorsal part) lesion coordinates in reference to bregma were anteroposterior (A/P) -2 $\mathrm{mm}$; mediolateral $(\mathrm{M} / \mathrm{L})-5 \mathrm{~mm}$ and dorsoventral $8.2 \mathrm{~mm}$. A midline incision was done and lambda and bregma were identified at the intersection of coronal and saggital sutures. A burr hole was then drilled in to rat brain using these coordinates. After hole was drilled, rats were 
cannulated with a 20 gauge cannula. Length of the cannula was kept at $8 \mathrm{~mm}$. After implanting the cannula, it was then fixed using denture material.

$5 \mu \mathrm{g} .2 \mu \mathrm{L}^{-1}$ of freshly prepared 6-OHDA solution was then injected at the rate of $1 \mu \mathrm{L} \cdot \mathrm{min}^{-1}$. After 14 days of 6-OHDA injection, rats which show at least 210 contralateral rotations in $30 \mathrm{~min}$ when challenged with apomorphine $\left(0.5 \mathrm{mg} \mathrm{kg}^{-1} \mathrm{~s} . \mathrm{c}\right)$ were selected for further study.

Proposed treatment from mangiferin $(15 \mu \mathrm{g}, 30 \mu \mathrm{g}$ and $45 \mu \mathrm{g})$ was done for 28 days, from day 14 to day 42. After treatment with mangiferin, rats were subjected to behavioural studies to evaluate effect of mangiferin on locomotor changes in 6-OHDA lesioned rats. After completion of study rats were sacrificed with high dose of anaesthesia (pentobarbital $100 \mathrm{mg} \cdot \mathrm{kg}^{-1}$ ) and their brain were taken out to perform biochemical and molecular studies.

\section{Drugs and Chemicals}

6-OHDA, Mangiferin, Levodopa, HEPES, $\mathrm{MgCl}_{2}$, EDTA, Hexadecyl-trimethyl-ammonium bromide, o-Dianisidine dihydrochloride, PMSF, tri-pyridyltriazine and apomorphine were purchased from Sigma Aldrich St. Louis, Montana, USA. ELISA kits for measuring NF-B, TNF-, IL-1, and IL-4and IL-6 were purchased from Cloud Clone Corp., Peoples Republic of China. Caspase 3 and Caspase 9 assay system was obtained from BioVisionInc, Milpitas, California, USA.

\section{Behavioral and Locomotor Analysis}

\section{Animal Activity Meter: Opto-Varimex-5 Auto-Track}

Opto-Varimex5 (Columbus Instruments, Columbus, Ohio, USA) is modern software that helps in quantification of locomotive parameters such as total distance travelled $(\mathrm{cm})$, average speed $\left(\mathrm{cm} . \mathrm{s}^{-1}\right)$, total ambulatory time $(\mathrm{s})$, resting time $(\mathrm{s})$ and stereotypic time (s).Any-maze Video Tracking System

Rat's behavioural and locomotive activity was evaluated utilizing Any-Maze video tracking system of Stoelting, USA. Rat was placed for a short time in an open field corner and the required parameters, including the distance travelled; average speed; freezing duration and episodes of freezing were chosen through Any-maze software and were recorded with the aid of over-mounted camera movement of rats.

\section{Cylinder Test}

Cylinder test assesses lop-sidedness in locomotor activity in rodents. This test measures the forelimb activity of rodents inside an open-top transparent plastic cylinder. Cylinder test assesses lop-sidedness in locomotor activity in rodents. This test measures the forelimb 
activity of rodents inside an open-top transparent plastic cylinder. The magnitude of forelimb activity of rats was measured when the rat places its entire paw on the cylinder wall for body support while rearing. A total of 20 such forelimb contacts were, measured for each rat. The numbers of impaired and non-impaired forelimb contacts were calculated as a percentage of total contacts [40].

\section{Grip Strength Meter}

Forelimb grip strength was measured using Grip Strength Meter (Columbus Instruments, USA).

\section{Cook's Pole Climbing Test}

This test was used to determine the latency to climb the pole by 6-OHDA lesioned rats. In pole climbing test, rats are accustomed to climb onto the pole to steer clear of the shock. A tone of $50 \mathrm{~Hz}$ and current of 1 mili ampere was passed onto wooden floor to condition the rats which is then succeeded by current of zero amperes as unconditioned stimuli. Time taken by the rats to climb the wooden pole (shock free zone) in the middle of instrument was then recorded [41].

\section{Stepping Test}

The stepping test was used to assess the contralateral forepaw's initiation deficiency. In this test, the number of adjustment steps taken by rats was recorded while rats travel sideways on a $60 \mathrm{~cm}$ wide flat surface with one of his forelimb being restrained [42].

\section{Estimation of oxidative stress markers}

\section{MDA levels in brain tissue homogenate}

After completion of the study animals were euthanized (pentobarbitone sodium $100 \mathrm{mg} \cdot \mathrm{kg}^{-}$ ${ }^{1}$ i.p) and their brain was isolated and homogenized. The homogenate thus obtained was assayed for the MDA concentration by the method of Ohkawa et al [43] and was expressed as nmol.mg- ${ }^{1}$ protein. Protein estimation was done by using method of Lowry et al [44].

\section{Myeloperoxidase assay in brain tissue homogenate}

Myeloperoxidase (MPO) activity was evaluated in to assess microglial activity as described by Barone et al. 1992 [45]. Rats were sacrificed by high dose of pentobarbitone sodium $100 \mathrm{mg} . \mathrm{kg}^{-1}$ i.p and brain was taken out and homogenized. Supernatant thus obtained was then assayed for MPO at $460 \mathrm{~nm}$ and was represented in $\mathrm{mU}_{\text {.gm }}{ }^{-1}$ weight of wet tissue.

\section{SOD activity in brain tissue homogenate}


Analysis of SOD activity in brain tissue homogenates was done by the method of Marklund and Marklund [46] and expressed in $\mathrm{U}_{\mathrm{gm}}{ }^{-1}$ of protein. Protein estimation was done by Lowry's method [44].

\section{Catalase assay in brain tissue homogenate}

Catalase activity in rat brain tissue homogenate was determined as per method described by Sinha et al. 1972 and Aebi et al. 1974 and was expressed as U.mg-1 of protein [47], [48].

\section{Total antioxidant capacity assay}

Evaluation of Total antioxidant capacity in striatum was done by ferric reduction antioxidant power (FRAP) assay [49].

\section{$\mathrm{Th}_{1} / \mathrm{Th}_{2}$ Cytokine assay}

Solid phase sandwich ELISA kits obtained from Diaclone, France were used in $\mathrm{Th}_{1}$ (IFN- $\gamma$ ) and $\mathrm{Th}_{2}$ (IL-4) cytokine assay. In this assay, monoclonal antibody specific for rat IL-4 and IFN- $\gamma$ were coated on to the wells of the micro titer strips. Antigen and antibodies were then incubated simultaneously at $37{ }^{\circ} \mathrm{C}$ for $1 \mathrm{hr}$. Streptavidin horseradish peroxidase and chromogen TMB (3, 3', 5, 5;-tetramethylbenzidine) were used in the revelation step. Rest of the protocol was followed as described in the assay kit. The plates were read on Microscan5405A (ECIL) and results were expressed in $\mathrm{pg} / \mathrm{ml}$.

\section{Pro-inflammatory (TNF- $\alpha, I L-1 \beta, I L-4$ and IL-6) cytokines estimation}

At the end of study all animals were sacrificed using high dose of anesthesia and their brain was isolated and homogenized. Tissue levels of pro-inflammatory cytokines TNF- $\alpha$, IL- $1 \beta$, IL-4 and IL-6was determined using commercially available enzyme linked immunosorbent assay (ELISA) kits from Cloud Clone Corp and was represented as $\mathrm{pg} \cdot \mu \mathrm{g}^{-1}$ tissue.

\section{$N F-\kappa B$ estimation}

At the end of study, rats were sacrificed using high dose of anesthesia and their brain was isolated and homogenized in $10 \%$ PBS. NF- $\kappa \mathrm{B}$ was then determined in brain tissue homogenates using commercially available ELISA kit from Cloud Clone Corp and results were expressed in pg. $\mu \mathrm{g}^{-1}$ tissue.

\section{Caspase-3 activity}

Caspase-3 activity was assayed using fluorometric assay system (Biovision, USA) brain tissue homogenates as per the manufacturer's protocol. Final reading was taken at 360/460 $\mathrm{nm}$ and was expressed in $\mu \mathrm{mol} . \mathrm{mg}^{-1}$ of protein.

\section{Caspase 9 activity}

Caspase-9 activity was calculated using the ready to use fluorometric assay system (BioVisionInc, USA). Aliquots of the brain tissue homogenate were re-suspended in lysis 
buffer and subjected to further homogenization and were assayed for Caspase 9 activity as per the manufacturer's protocol.Final reading was taken at $400 / 505 \mathrm{~nm}$ respectively and expressed in $\mu \mathrm{mol} . \mathrm{mg}^{-1}$ of protein.

\section{Cyclooxygenase Activity}

Cyclooxygenase (Cox1 and Cox 2) activity was measured in rat brain tissue homogenates using Cox-1 and Cox-2 ELISA kit from CUSABIO Houston, Texas, USA.

\section{Statistics}

The data obtained was analyzed by two-way ANOVA followed by Newman Keul posthoc test for multiple group analysis by using Graph Pad Prism 6.0. The p value <0.05 was considered as significant in all parameters. The data was analyzed and represented as Mean \pm SEM.

\section{Results}

\section{Effect of mangiferin on ambulatory, stereotypic and resting time in 6-OHDA lesioned rats}

Ambulatory, stereotypic and resting times were evaluated in rats after 42 days of 6-OHDA lesioning through activity meter (OptoVarimex 5 Columbus Instruments, USA). 6- OHDA lesioning significantly reduces ambulatory time while increase in stereotypic and resting time was observed after 42 days of 6-OHDA induced hemi-parkinsonism. These, 6-OHDA induced changes in hemi-parkinsonian rats were significantly improved by treatment with mangiferin $(15-45 \mu \mathrm{g})$. Mangiferin $(15-45 \mu \mathrm{g})$ significantly increases ambulatory time and diminishes stereotypic and resting time $(\mathrm{p}<0.005)$. Treatment with levodopa $10 \mathrm{mg} \cdot \mathrm{kg}^{-1}$ alone and in combination with mangiferin $45 \mu \mathrm{g}$ considerably increases total ambulatory time while significant decrease in stereotypic and resting time was observed in hemi-parkinsonian rats (F $(2,12)=8.424 ; \mathrm{p}=0.0052)$ as shown in Fig. 1 .

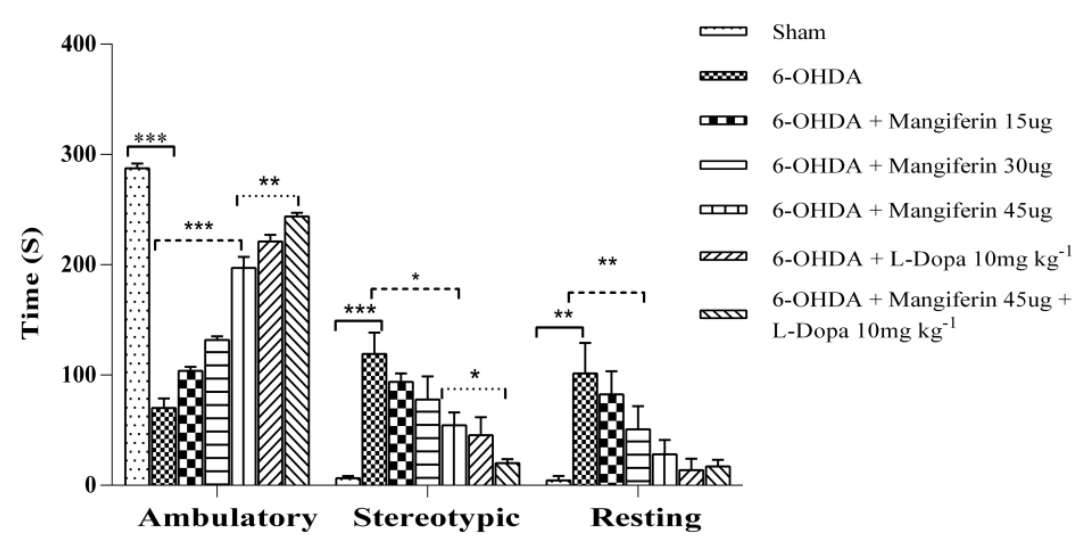


Figure 1: Effect of mangiferin on ambulatory, stereotypic and resting time (s). Treatment with mangiferin reverses 6-OHDA induced changes in ambulatory, stereotypic and resting time in a dose dependent manner.

Effect of mangiferin on distance travelled, average speed, time mobile and number of mobile episodes in 6-OHDA lesioned rats

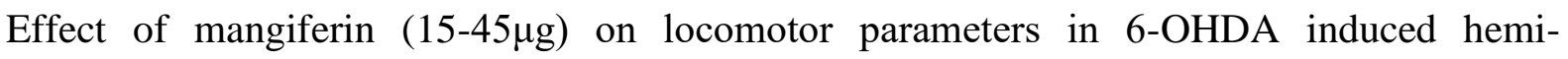
parkinsonism rats was assessed after 42 days of 6-OHDA lesioning. Significant decrease in locomotor parameters of number of mobile and freezing episodes, distance travelled, time mobile, time immobile and time freezing and average speed were observed in rats after 6OHDA lesioning, while substantial increase in time freezing and time immobile was observed $(\mathrm{p}<0.005)$. Treatment with mangiferin $(15-45 \mu \mathrm{g})$ markedly enhances the locomotor activity. Significant increase in distance travelled, average speed, time mobile, number of active and freezing episodes was observed in hemi-parkinsonism rats treated with mangiferin $(15-45 \mu \mathrm{g})$. Treatment with levodopa $10 \mathrm{mg} \cdot \mathrm{kg}^{-1}$ also significantly improves these locomotor parameters $(\mathrm{p}<0.005)$. Marked improvement in these parameters was also observed in rats treated with combinatorial therapy of mangiferin $45 \mu \mathrm{g}$ and levodopa $10 \mathrm{mg} \cdot \mathrm{kg}^{-1}(\mathrm{~F}(6,14)=$ 29.56; p<0.0001) (Fig. 2a-2d).
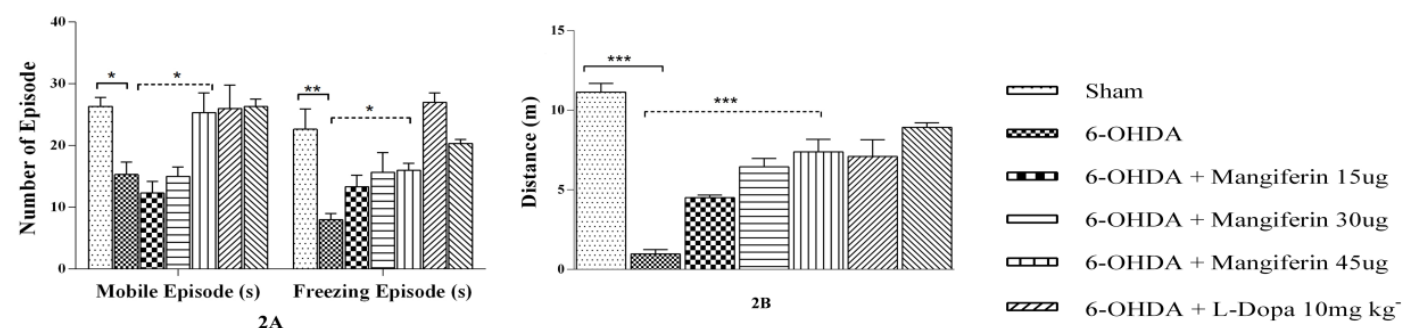

$2 \mathrm{~A}$
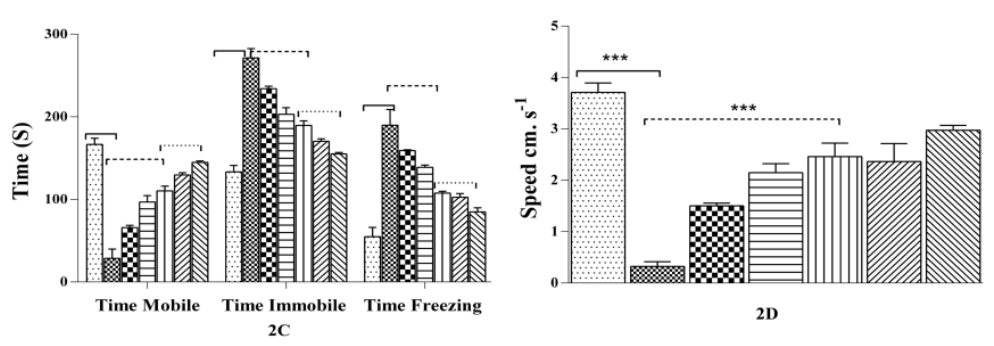

6-OHDA + L-Dopa $10 \mathrm{mg} \mathrm{kg}^{-1}$

6-OHDA + Mangiferin 45ug + L-Dopa $10 \mathrm{mg} \mathrm{kg}^{-1}$

Figure 2: (a) Effect of Mangiferin on 6-OHDA induced changes in mobile and freezing episode, (b) Effect of Mangiferin on 6-OHDA induced changes on total distance travel, (c) Effect of Mangiferin on 6-OHDA induced changes in time mobile, time immobile and time freezing time, (d) Effect of Mangiferin on 6-OHDA induced changes in mean speed. 


\section{Effect of Mangiferin on 6-OHDA induced changes in track plot of rats}

Heat Map of hemi-parkinsonian rats also showed that locomotor activity was markedly suppressed after 6-OHDA lesioning. Daily treatment with mangiferin $(15-45 \mu \mathrm{g})$ for 28 days extensively improves locomotor activity which was conspicuous through their heat map. Treatment with levodopa $10 \mathrm{mg} \cdot \mathrm{kg}^{-1}$ alone and in combination with mangiferin $45 \mu \mathrm{g}$ also significantly improves locomotor activity as evident through their heat map (Fig. 3a-3g).

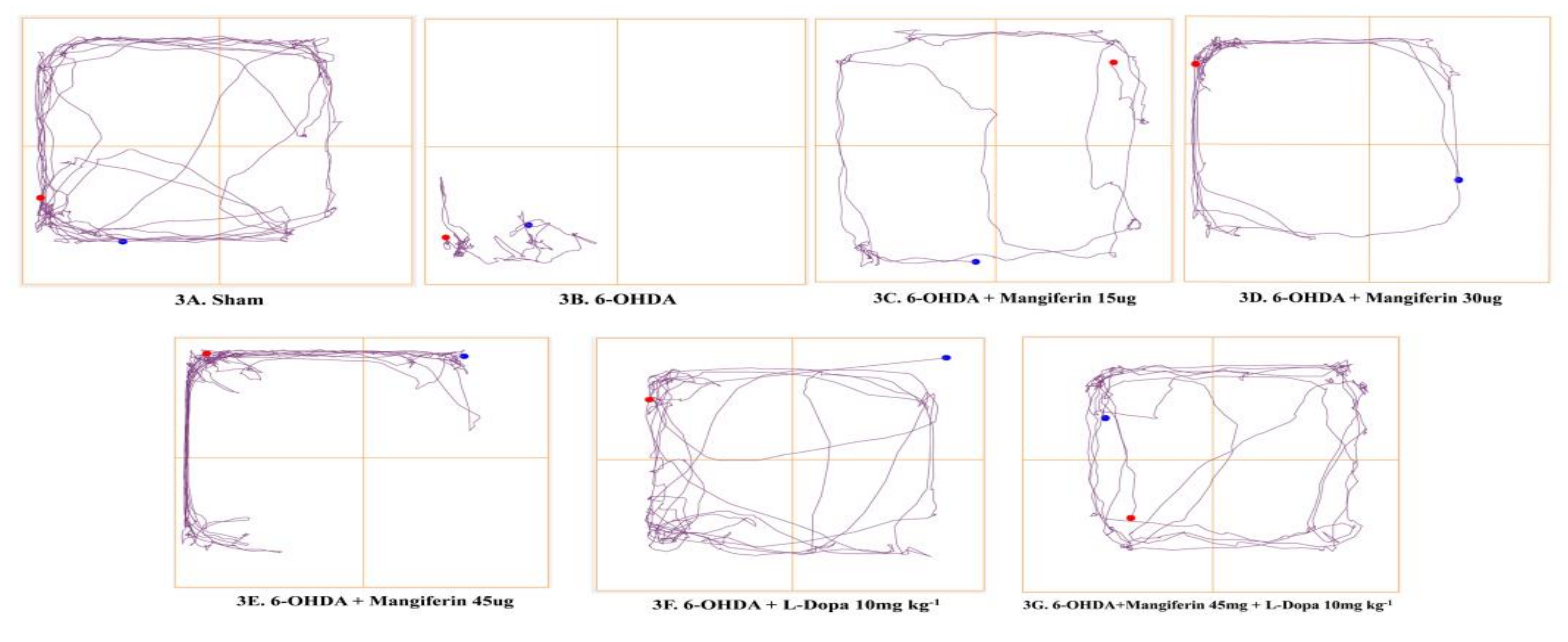

Figure 3: (a) Track plot of Sham group, (b) Track plot of 6-OHDA lesioned rats, (c) Effect of mangiferin $(15 \mu \mathrm{g})$ on track plot of 6-OHDA lesioned rats, (c) Effect of mangiferin $(30 \mu \mathrm{g})$ on track plot of 6-OHDA lesioned rats, (d) Effect of mangiferin $(15 \mu \mathrm{g})$ on track plot of 6-OHDA lesioned rats, (e) Effect of mangiferin $(45 \mu \mathrm{g})$ on track plot of 6-OHDA lesioned rats, (f) Effect of levodopa $10 \mathrm{mg} . \mathrm{kg}^{-1}$ on track plot of 6-OHDA lesioned rats, (g) Effect of mangiferin $45 \mu \mathrm{g}$ and Levodopa $10 \mathrm{mg} \cdot \mathrm{kg}^{-1}$ on track plot of 6-OHDA lesioned rats.

\section{Effect of mangiferin on sensorimotor forelimb function in 6-OHDA lesioned rats}

Sensorimotor forelimb function was measured in 6-OHDA induced hemi-parkinsonian rats to reckon the asymmetry of forelimb function. Significant diminution in spontaneous use of contralateral front paw was observed in rats after lesioning with 6-OHDA. Upswing in the contralateral forelimb use was observed in lesioned rats after treatment with mangiferin (15$45 \mu \mathrm{g})$ on daily basis for 28 days. Treatment with levodopa $10 \mathrm{mg} \cdot \mathrm{kg}^{-1}$ also spurts contralateral forelimb use in parkinsonian rats. Significant upturn in the use of contralateral 
forelimb was also observed in 6-OHDA lesioned rats treated with combination of levodopa $10 \mathrm{mg} . \mathrm{kg}^{-1}$ and mangiferin $\left.45 \mu \mathrm{g}\right)(\mathrm{F}(8,18) 20.70 ;=\mathrm{p}<0.0001)$ (Fig. 4a).

\section{Effect of mangiferin on grip strength of 6-OHDA lesioned rats}

Grip strength of rats was recorded after 42 days post 6-OHDA lesion using Grip Strength Meter (Columbus Instruments, USA). Grip strength of rats decreased significantly post 6OHDA lesion. Daily treatment with mangiferin $(15-45 \mu \mathrm{g})$ very much increases the grip strength in hemi-parkinsonian rats. Levodopa $10 \mathrm{mg} \cdot \mathrm{kg}^{-1}$ significantly increases the grip strength in lesioned rats. Combinatorial therapy of levodopa $10 \mathrm{mg} \cdot \mathrm{kg}^{-1}$ and mangiferin $45 \mu \mathrm{g}$ largely increases the grip strength of hemi-parkinsonian rats $(F(6,14)=42.30$; $p<0.0001)$ for all groups) (Fig. 4b).

\section{Effect of mangiferin on cook's pole climbing test in 6-OHDA lesioned rats}

6-OHDA lesioning significantly increases the time to climb the pole as compared to rats in which sham surgery was performed. Daily treatment with mangiferin $(15-45 \mu \mathrm{g})$ for 28 days significantly decreases the time to climb the pole in hemi-parkinsonian rats. Significant decrease in time to climb the pole was observed in rats treated with levodopa $10 \mathrm{mg} \cdot \mathrm{kg}^{-1}$. Combinatorial therapy with levodopa $10 \mathrm{mg} \cdot \mathrm{kg}^{-1}$ and mangiferin $45 \mu \mathrm{g}$ also significantly decreases the time to climb the pole in hemi-parkinsonian rats $(F(6,14)=27.84 ; p<0.0001)$ (Fig4c).

\section{Effect of mangiferin on forelimb akinesia in 6-OHDA lesioned rats}

Forelimb akinesia in 6-OHDA lesioned rats was assessed through stepping test. 6-OHDA lesioning significantly decreases the number of adjusting steps of contralateral forelimb which is suggestive of forelimb akinesia in rats. Treatment with mangiferin $(15-45 \mu \mathrm{g})$ significantly decreases forelimb akinesia by increasing number of adjusting steps taken by contralateral forelimb in lesioned rats. Substantial decrease in forelimb akinesia was also observed in rats treated with levodopa $10 \mathrm{mg} \cdot \mathrm{kg}^{-1}$ alone and in combination with mangiferin $45 \mu \mathrm{g}(\mathrm{F}(8,18)=2.556 ; \mathrm{p}<0.0001)($ Fig. $4 \mathrm{~d})$. 

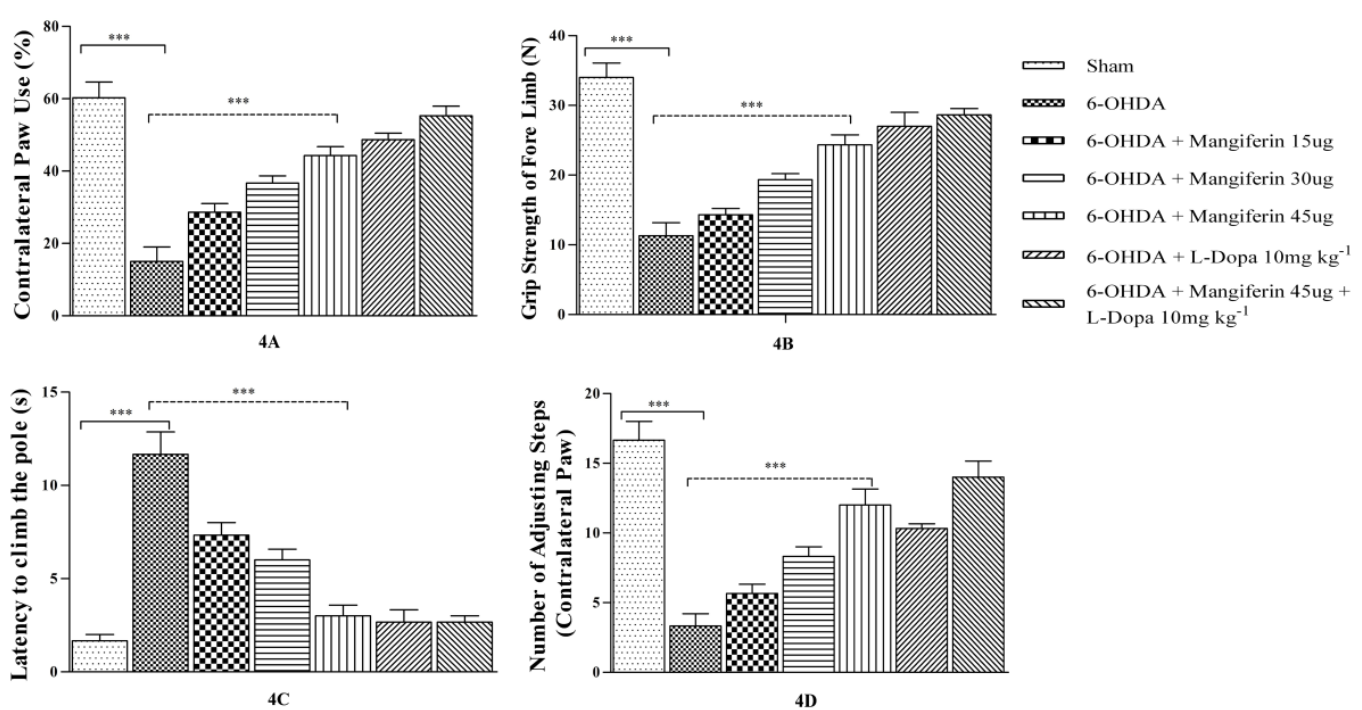

Figure 4: (a) Effect of mangiferin on sensorimotor forelimb function in 6-OHDA lesioned rats, (b) Effect of mangiferin on grip strength of 6-OHDA lesioned rats, (c) Effect of mangiferin on 6-OHDA lesioned rats on cook pole climbing test, (d) Effect of mangiferin in 6-OHDA lesioned rats on forelimb akinesia. Effect of mangiferin on MDA concentration in 6-OHDA lesioned rats MDA, end product of lipid peroxidation was measured in brain tissue of 6-OHDA lesioned rats to detect oxidative stress. Lesioning with 6-OHDA significantly increases the MDA concentration as compared to sham operated rats. Treatment with mangiferin $(15-45 \mu \mathrm{g})$ for 28 ameliorates this 6-OHDA induced increase in MDA concentration. Treatment with levodopa $10 \mathrm{mg} \cdot \mathrm{kg}^{-1}$ has no significant effect on MDA concentration, while its combination with mangiferin $45 \mu \mathrm{g}$ significantly reduces MDA concentration $(F(6,14)=82.84 ; \mathrm{p}<0.0001)$ (Fig. 5a).

\section{Effect of mangiferin on myeloperoxidase activity in 6-OHDA lesioned rats}

6-OHDA lesioning in rats leads to neuro-inflammation and microglial activation. Myeloperoxidase activity was assayed as an indicator of inflammatory response in PD. 6OHDA lesioning substantially increases myeloperoxidase activity as compared to sham surgery rats. Mangiferin $(15-45 \mu \mathrm{g})$ treatment for 28 days significantly decreases myeloperoxidase activity in hemi-parkinsonian rats. Levodopa $10 \mathrm{mg} \cdot \mathrm{kg}^{-1}$ has no significant effect on myeloperoxidase activity, while its combination with mangiferin $45 \mu \mathrm{g}$ significantly decreases myeloperoxidase activity $(\mathrm{F}(6,14)=81.57$; p<0.0001) (Fig. 5b).

Effect of mangiferin on SOD and Catalase activity in 6-OHDA lesioned rats 
SOD activity was measured to estimate oxidative stress in 6-OHDA lesioned rats. SOD activity was observed to be significantly reduced in hemi-parkinsonian rats. Mangiferin (15$45 \mu \mathrm{g})$ treatment for 28 days significantly increases SOD activity in hemi-parkinsonian rats. Treatment with levodopa $10 \mathrm{mg} \cdot \mathrm{kg}^{-1}$ has no significant effect on SOD activity. Combinatorial therapy of levodopa $10 \mathrm{mg} \cdot \mathrm{kg}^{-1}$ and mangiferin $45 \mu \mathrm{g}$ substantially increases SOD activity in hemi-parkinsonian rats $(\mathrm{p}<0.005)($ Fig.5c).

Significant decrease in catalase activity was observed in rats after 6-OHDA lesioning. Treatment with mangiferin $(15-45 \mu \mathrm{g})$ alone and in combination with levodopa significantly increases catalase activity in hemi-parkinsonian rats (Fig. 5c) $(\mathrm{F}(1,8)=7.05 ; \mathrm{p}<0.029)$.

\section{Effect of mangiferin on total anti-oxidant capacity in 6-OHDA lesioned rats}

Total anti-oxidant capacity assay was done to gauge any change in anti-oxidant status in nigrostriatal tissue of 6-OHDA lesioned rats. 6-OHDA lesioning significantly reduces total anti-oxidant capacity thereby increasing total ROS capacity and oxidative stress. Daily treatment with mangiferin $(15-45 \mu \mathrm{g})$ markedly increases total anti-oxidant capacity in lesioned rats. Levodopa $10 \mathrm{mg} . \mathrm{kg}^{-1}$ has no significant effect on total anti-oxidant capacity in hemi-parkinsonian rats. Combinative therapy with mangiferin $45 \mu \mathrm{g}$ and levodopa $10 \mathrm{mg} \cdot \mathrm{kg}^{-1}$ significantly increases total anti-oxidant capacity in 6-OHDA lesioned rats $(\mathrm{F}(6,14)=38.85$; $\mathrm{p}=0.0001)$ (Fig. 5d).
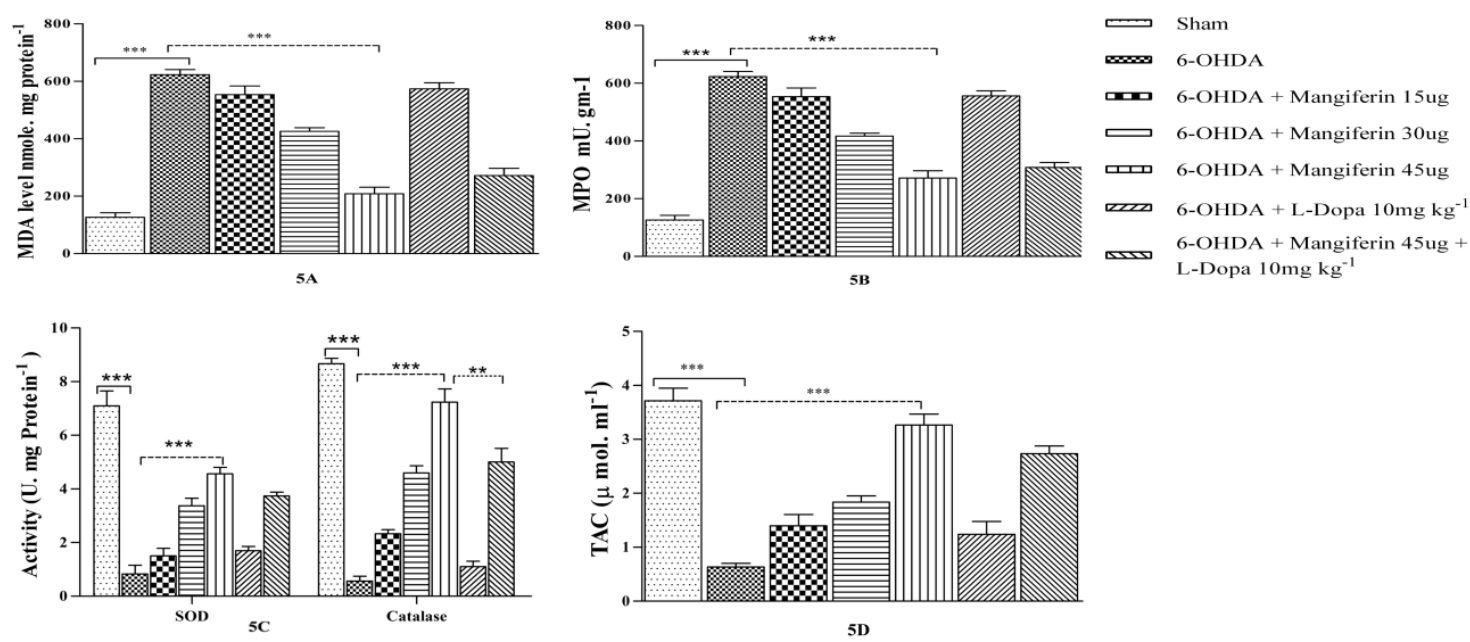

5D

Figure 5: (a) Effect of mangiferin on MDA concentration in 6-OHDA lesioned rats, (b) Effect of mangiferin on myeloperoxidase activity in 6-OHDA lesioned rats, (c) Effect of mangiferin 
on SOD and Catalase activity in 6-OHDA lesioned rats, (d) Effect of mangiferin on total antioxidant capacity in 6-OHDA lesioned rats.

\section{Effect of mangiferin on 6-OHDA induced changes in $\mathrm{Th}_{1}$ and $\mathrm{Th}_{2}$ cytokine assay}

It was observed that 6-OHDA lesioning significantly increases $\mathrm{Th}_{1}$ and $\mathrm{Th}_{2}$ cytokines levels. Defense mechanism $\mathrm{Th}_{1}$ cytokines was more enhanced as compared to the $\mathrm{Th}_{2}$ cells dependent defense mechanism. Treatment with mangiferin $(15-45 \mu \mathrm{g})$ significantly reduces $\mathrm{Th}_{1}$ (IFN- $\gamma$ ) and $\mathrm{Th}_{2}$ (IL-4) cytokines levels (Fig. 6). Levodopa $10 \mathrm{mg} \cdot \mathrm{kg}^{-1}$ has no significant effect on $\mathrm{Th}_{1}$ and $\mathrm{Th}_{2}$ cytokines levels $(\mathrm{F}(1,28)=12.94 ; \mathrm{p}=0.0012)$ (Figure 6).

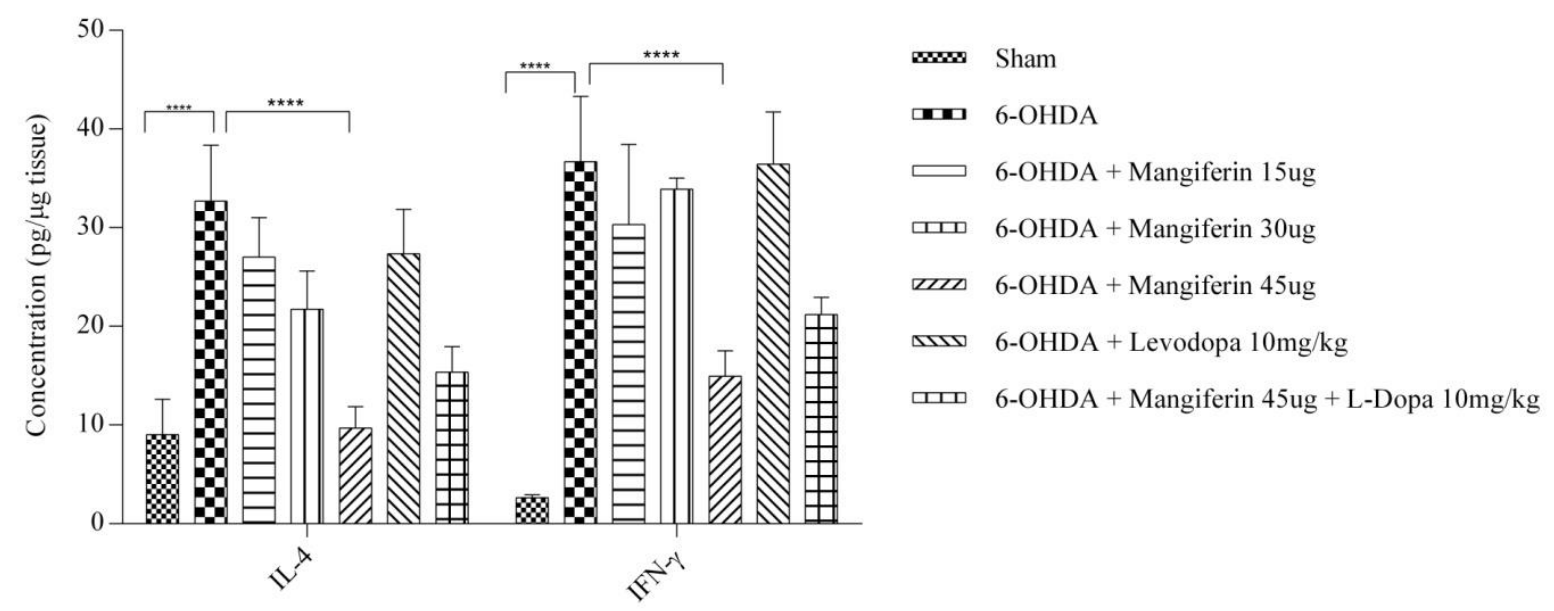

Figure 6: Effect of mangiferin on Th1 and Th2 cytokine concentration in 6-OHDA lesioned rats

\section{Effect of mangiferin on cytokine concentration in 6-OHDA lesioned rats}

6-OHDA lesioning significantly increases concentration of pro-inflammatory cytokines (TNF- $\alpha$, IL-6 and IL-1 $\beta$ ) in parkinsonian rats compared to sham surgery rats. Daily treatment with mangiferin $(15-45 \mu \mathrm{g})$ attenuates this 6-OHDA induced increase in concentration of these pro-inflammatory cytokines. Treatment with levodopa $10 \mathrm{mg}^{\mathrm{kg}} \mathrm{kg}^{-1}$ has no significant effect on concentration of pro-inflammatory cytokines. Levodopa $10 \mathrm{mg} \cdot \mathrm{kg}^{-1}$ in combination with mangiferin $45 \mu \mathrm{g}$ significantly reduces concentration of these cytokines $(\mathrm{F}(2,42)=$ 41.58; $\mathrm{p}<0.0001)$ (Table 1). 
Table-1: Cytokine levels of brain tissue homogenate 6-OHDA lesioned rats (data in Mean $\pm \operatorname{SEM})(n=8 /$ group $)$

\begin{tabular}{|c|c|c|c|}
\hline Treatment & $\begin{array}{c}\text { IL-6 } \\
\text { (Pg/ml) }\end{array}$ & $\begin{array}{c}\text { IL-1及 } \\
\text { (Pg/ml) }\end{array}$ & $\begin{array}{r}\text { TNF-a } \\
(\mathrm{Pg} / \mathrm{ml})\end{array}$ \\
\hline Sham & $4.3 \pm 0.9$ & $11.8 \pm 1.5$ & $12.1 \pm 1.7$ \\
\hline 6-OHDA & $87.1 \pm 1.3^{*}$ & $70.7 \pm 3.9^{*}$ & $65.8 \pm 0.9 *$ \\
\hline 6-OHDA + Mangiferin $(15 \mu \mathrm{g})$ & $60.6 \pm 0.9^{\mathrm{a}}$ & $51.2 \pm 1.4^{\mathrm{a}}$ & $59.4 \pm 1.6$ \\
\hline 6-OHDA + Mangiferin $(30 \mu \mathrm{g})$ & $38.3 \pm 0.5^{\mathrm{a}}$ & $31.5 \pm 2.1^{\mathrm{a}}$ & $53.1 \pm 0.7^{\mathrm{a}}$ \\
\hline 6-OHDA + Mangiferin $(45 \mu \mathrm{g})$ & $11.6 \pm 0.8^{\mathrm{a}}$ & $14.9 \pm 0.9^{\mathrm{a}}$ & $25.2 \pm 2.3^{\mathrm{a}}$ \\
\hline $6-O H D A+$ Mangiferin $(45 \mu \mathrm{g})$ & $24.3 \pm 0.7^{b}$ & $41.5 \pm 156$ & $36.9 \pm 0.9$ \\
\hline \multicolumn{4}{|l|}{+} \\
\hline \multicolumn{4}{|l|}{ Levodopa (10 mg.kg $\left.{ }^{-1}\right)$} \\
\hline 6-OHDA + Levodopa (10 mg. $\left.\mathrm{kg}^{-1}\right)$ & $74.9 \pm 0.3$ & $64.7 \pm 1.6$ & $59.3 \pm 0.9$ \\
\hline
\end{tabular}

$* \mathrm{p}<0.001$ compared to sham, ${ }^{\mathrm{a}} \mathrm{p}<0.05$ compared to 6-OHDA

\section{Effect of mangiferin on $\mathrm{NF}-\kappa \mathrm{B}$ concentration in 6-OHDA lesioned rats}

$\mathrm{NF}-\mathrm{\kappa B}$ is the master controller of inflammation. Increased oxidative stress and neuroinflammation increases NF- $\mathrm{KB}$ concentration in 6-OHDA lesioned rats as compared to sham surgery rats. Canonical pathway of $\mathrm{NF}-\kappa \mathrm{B}$ thus activated was inhibited by treatment with

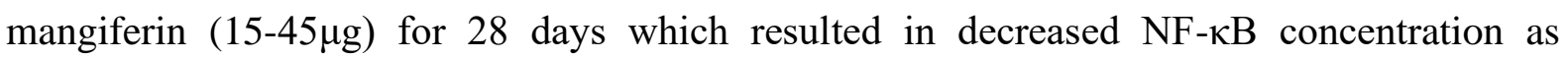
compared to 6-OHDA lesioned rats which received saline. Treatment with levodopa $10 \mathrm{mg} . \mathrm{kg}^{-1}$ has no effect on NF- $\mathrm{B}$ concentration in hemi-parkinsonian rats. Treatment with combination of levodopa $10 \mathrm{mg} \cdot \mathrm{kg}^{-1}$ with mangiferin $45 \mu \mathrm{g}$ significantly decreases $\mathrm{NF}-\kappa \mathrm{B}$ concentration in striatum of 6-OHDA lesioned rats $(F(6,14)=36.13 ; p=0.0001)$ (Table 2). 
Table-2: NF- $\kappa B$ concentration in brain tissue homogenate of 6-OHDA lesioned rats on day 28 (data are in Mean \pm SEM) $(n=8 /$ group)

\begin{tabular}{lc}
\hline & $\begin{array}{c}\text { NF- } \mathbf{k B} \\
(\mathbf{P g} / \mathbf{m l})\end{array}$ \\
\hline Sham & $5.7 \pm 0.9$ \\
6-OHDA & $41.3 \pm 6.1^{*}$ \\
6-OHDA + Mangiferin $(15 \mu \mathrm{g})$ & $37.6 \pm 2.9^{\mathrm{a}}$ \\
6-OHDA + Mangiferin $(30 \mu \mathrm{g})$ & $32.3 \pm 4.7^{\mathrm{a}}$ \\
6-OHDA + Mangiferin $(45 \mu \mathrm{g})$ & $18.6 \pm 1.8^{\mathrm{a}}$ \\
6-OHDA + Mangiferin $(45 \mu \mathrm{g})$ & $21.9 \pm 1.3$ \\
$\quad+$ & \\
Levodopa (10 mg. $\left.\mathrm{kg}^{-1}\right)$ & \\
6-OHDA + Levodopa $\left(10 \mathrm{mg} \cdot \mathrm{kg}^{-1}\right)$ & $34.9 \pm 0.3$ \\
\hline
\end{tabular}

$* \mathrm{p}<0.001$ compared to Sham, ${ }^{\mathrm{a}} \mathrm{p}<0.05$ compared to 6-OHDA

\section{Effect of mangiferin on caspase-3 activity in 6-OHDA lesioned rats}

Lesioning with 6-OHDA significantly increases activity of caspase-3 as compared to sham

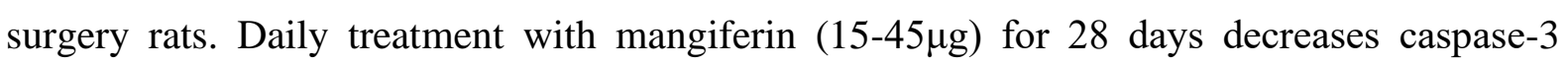
activity to a large extent in striatum of lesioned rats. Treatment with levodopa $10 \mathrm{mg}^{\mathrm{kg}} \mathrm{kg}^{-1}$ has no significant effect on caspase-3 activity while its combination with mangiferin $45 \mu \mathrm{g}$ significantly decreases caspase-3 activity in 6-OHDA lesioned rats $(\mathrm{F}(6,14)=36.13$; $\mathrm{p}=0.0001)$ (Fig. 7).

\section{Effect of mangiferin on caspase-9 activity in 6-OHDA lesioned rats}

Significant increase in caspase-9 activity was observed in striatum of rats after lesioning with 6-OHDA. Treatment with mangiferin $(15-45 \mu \mathrm{g})$ for consecutive 28 days significantly reduces caspase-9 activity in 6-OHDA lesioned rats. Treatment with levodopa $10 \mathrm{mg}^{-\mathrm{kg}^{-1}}$ has no considerable effect on caspase-9 activity. Combination of levodopa $10 \mathrm{mg}^{\mathrm{kg}} \mathrm{kg}^{-1}$ with mangiferin $45 \mu \mathrm{g}$ substantially reduces caspase- 9 activity $(F(5,24)=87.14 ; p=0.0001)$ (Fig. 7). 


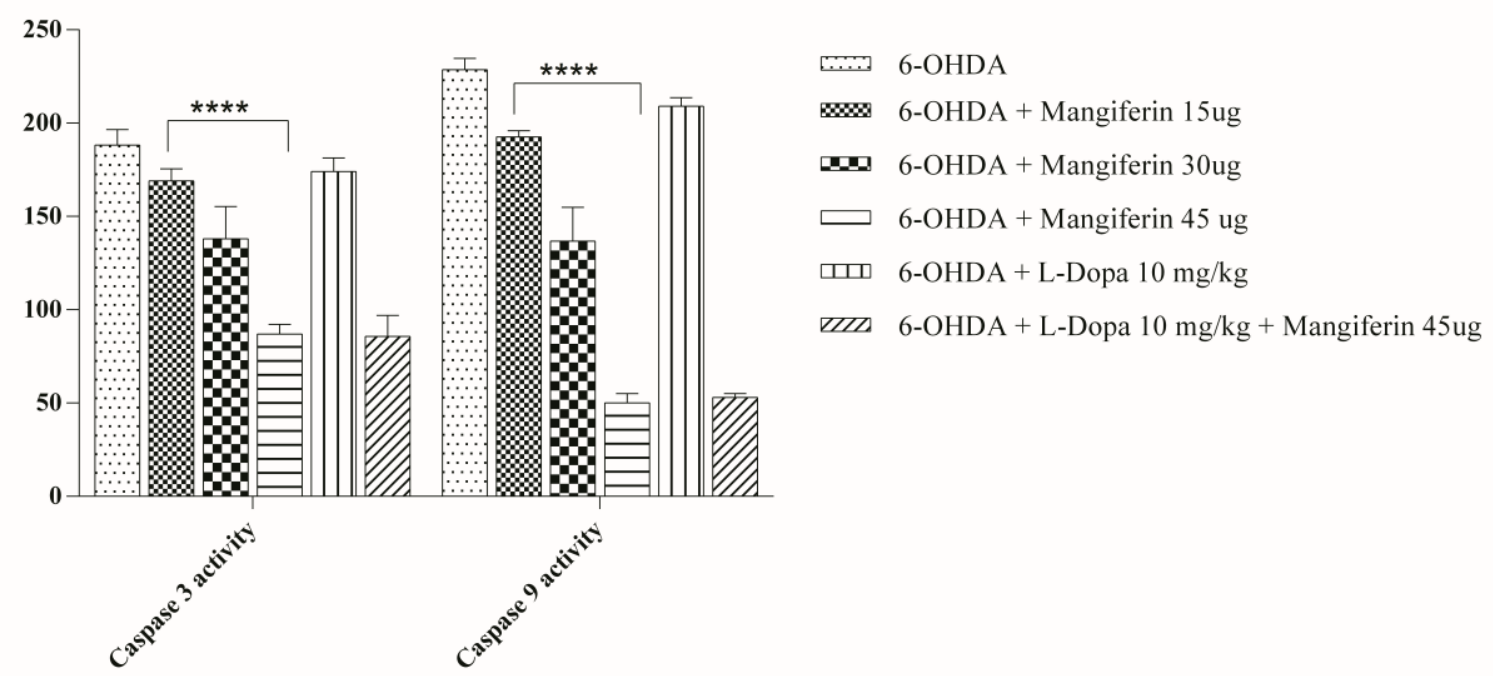

Figure 7: Effect of mangiferin on 6-OHDA induced changes in expression of Caspase-3 and Caspase-9.

\section{Effect of mangiferin on Cox activity in 6-OHDA lesioned rats}

Significant increase in Cox (Cox 1 and Cox 2) activity was observed in striatum of rats after lesioning with 6-OHDA. Treatment with mangiferin $(15-45 \mu \mathrm{g})$ for consecutive 28 days significantly reduces both Cox 1 and Cox 2 activity in 6-OHDA lesioned rats. Treatment with levodopa 10mg.kg-1 has no considerable effect on Cox activity. Combination of levodopa 10mg.kg ${ }^{-1}$ with mangiferin $45 \mu \mathrm{g}$ reduces both Cox1 and Cox 2 activity $(\mathrm{F}(1,28)=445.9 ; \mathrm{p}<$ 0.0001) (Fig. 8).

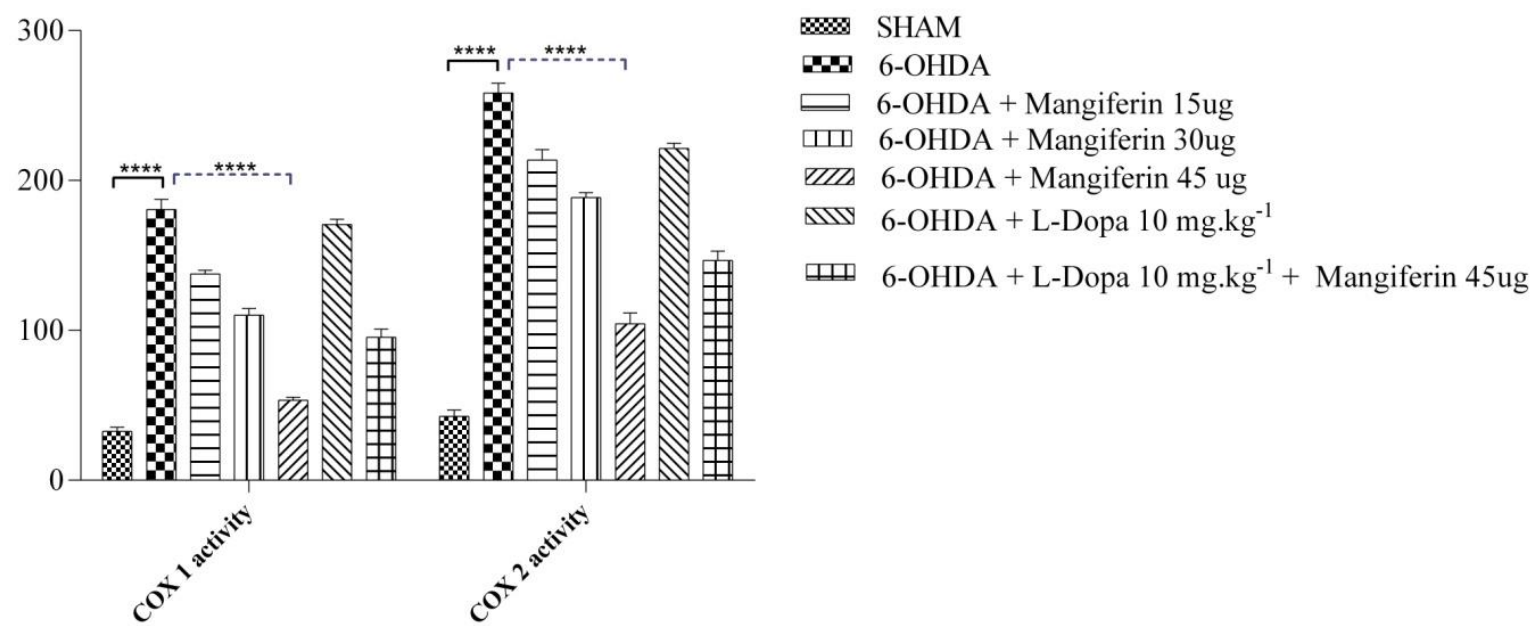

Figure 8: Effect of mangiferin on 6-OHDA induced changes on expression of Cox-1 and Cox-2 


\section{Discussion}

Levodopa is the mainstay of current pharmacotherapy of PD; however, owing to its autooxidant property, it could be a necessary evil. Thus, due to its auto-oxidant nature, levodopa fails to stop the disease progression. Due to its auto-oxidant nature levodopa promotes the disease progression by increasing oxidative stress and stimulating TNF- $\alpha$ secretion which then leads to neuro-inflammation and subsequent death of dopaminergic neurons $[12,50]$, [51]. Therefore, in this study we have tried to evaluate neuro-protective effect of NF- $\mathrm{B}$ inhibitor mangiferin which also has anti-oxidant property and develop a combination therapy of mangiferin and levodopa to top off the dopamine in striatum and to arrest the disease progression.

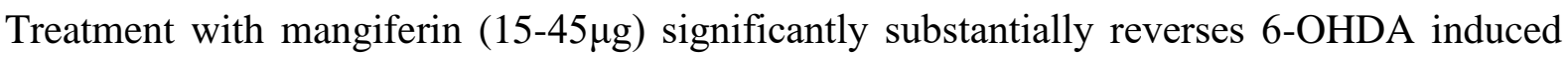
changes in locomotor parameters of ambulatory time, stereotypic and resting time. This could be, attributed to the rescue of dopaminergic from the death pathways due to its anti-apoptotic, anti-inflammatory and anti-oxidant property.

6-ODA injection in substantia nigra results in degeneration of about $60-80 \%$ of dopaminergic neurons, which results in dopamine deficiency in caudate nucleus, nucleus accumbens and ventral striatum along with other areas of the brain. This deficiency of dopamine in key functional areas of the brain leads to the breakdown of the circadian rhythm of rats, which is responsible for the increase in some of the stereotypic behaviour in rats after 6-OHDA lesioning. Treatment with mangiferin decreases these behaviour changes by preventing the apoptosis of dopaminergic neurons, which leads to an increase in the availability of dopamine. Supplementing mangiferin treatment with levodopa $10 \mathrm{mg} \cdot \mathrm{kg}^{-1}$ further improves this improvement in stereotypic behavior due to decreased apoptosis and increased dopamine availability, which results in restoration of the circadian rhythm.

Mangiferin also decreases resting time in 6-OHDA lesioned rats due to increase availability of dopamine in the striatum region due to halt in degeneration of neurons from the striatum region.

6-OHDA lesioning substantially decreases locomotive parameters such as total distance travelled, average speed, number of mobile episodes and time mobile. Treatment with mangiferin and levodopa substantially reversed this decrease in locomotive parameters. This improvement in locomotive parameters of time mobile, mobile episodes, average speed and total distance travelled could be ascribed to increase availability of dopamine in striatum region, which then leads to partial restoration of indirect pathway of dopamine receptors in striatum. 
In 6-OHDA only group, freezing episodes were lesser compared to treatment groups. Mangiferin increases the number of freezing episodes. This increase in freezing episodes is associated with tardive dyskinesia, while the only logical conclusion of lesser freezing episodes in the 6-OHDA only group would be akinesia due to dopamine deficiency in thestriatum.

Track plots of these rats further corroborate the improvement in the movement of rats after treatment with mangiferin. Moreover, supplementation of mangiferin $45 \mu \mathrm{g}$ with levodopa 10 $\mathrm{mg} \cdot \mathrm{kg}^{-1}$ results in a maximum improvement in all locomotive parameters due to enhanced availability of dopamine.

6-OHDA lesioning results in a severe movement deficit in rats due to decreased availability of dopamine in the striatum and other regions of the brain. This movement deficit was significantly reversed by treatment with mangiferin $(15-45 \mu \mathrm{g})$ alone and in combination with levodopa $10 \mathrm{mg} \cdot \mathrm{kg}^{-1}$.

Decreased grip strength is one of the earliest measures of severity of disease progression. The results of this study indicate that lesioning with 6-OHDA significantly reduces grip strength in rats and they have difficulty in grasping. 6-OHDA lesioning results in reduction of dopamine from nigrostriatal area, which then results in increased tonic inhibition of thalamus. This, increased inhibition of thalamus then results decreased excitation of cortex area.

Treatment with mangiferin significantly increases grip strength in hemi-parkinsonian rats, owing to its anti-apoptotic and anti-inflammatory property. Treatment with levodopa also significantly reverses the 6-OHDA induced changes in grasping capacity of rats. Maximum increase in grip strength was observed in rats treated with combinatorial therapy of levodopa $10 \mathrm{mg} . \mathrm{kg}^{-1}$ and mangiferin $45 \mu \mathrm{g}$ as it ought to both replenish the depleted dopamine in the striatum and halt the disease progression by stopping neuro-inflammation and subsequent degeneration of dopaminergic neurons.

On the expected lines, treatment with mangiferin significantly reduces the reaction time in cook's pole climbing test due to increased motor activity in hemi-parkinsonian rats. Maximum increase in this motor activity was observed in rats treated with combination of mangiferin $45 \mu \mathrm{g}$ and levodopa $10 \mathrm{mg} \cdot \mathrm{kg}^{-1}$.

Mangiferin also attenuates 6-OHDA induced sensorimotor forelimb function and forelimb akinesia in hemi-parkinsonian rats. Maximum increase in these gait analysis parameters was observed in rats treated combinative therapy of mangiferin $45 \mu \mathrm{g}$ and levodopa $10 \mathrm{mg} . \mathrm{kg}^{-1}$.

Treatment with mangiferin $15-45 \mu \mathrm{g}$ significantly reduces oxidative stress by decreasing MDA concentration due to its anti-oxidant property which is due to its activation of NRF2- 
ARE pathway. Mangiferin promotes the nuclear translocation of NRF2 which thus results in increased nuclear expression of NRF2. Furthermore, treatment with mangiferin also up regulates the expression of NQO1 and promotes the binding NRF2 with NQO1-ARE complex. Increased expression of NRF2 then stimulates the expression of anti-oxidant enzymes such as SOD and Catalase and increases the total anti-oxidant capacity of 6-OHDA lesioned rats [52].

Treatment with levodopa has no significant effect on these oxidative stress markers due to its auto-oxidant property. Metabolism of levodopa increases oxidative stress burden by generating free radicals and molecules like $\mathrm{H}_{2} \mathrm{O}_{2}$. It also reacts with iron present in brain to increase oxidative stress.

Myeloperoxidase activity which measured index of inflammation and microglial activation was significantly reduced by treatment with mangiferin $15-45 \mu \mathrm{g}$ due to its property of inhibiting pro-inflammatory cytokine TNF- $\alpha$ and COX pathway. Mangiferin substantially reduces the transcript activity of both Cox-1 and Cox-2, by inhibiting the nuclear translocation of NF- $\kappa \mathrm{B}$, which is crucial for expression of pro-inflammatory factors such as Cox-1, Cox-2 and TNF- $\alpha$.

Levodopa has no significant effect on myeloperoxidase activity as it promotes inflammation by stimulating TNF- $\alpha$ and IL-4 secretion.

6-OHDA lesioning considerably increased the concentration of pro-inflammatory cytokines TNF- $\alpha$, IL-4, IL-6 and IL-1 $\beta$. Mangiferin significantly reduces concentration of these proinflammatory cytokines. It inhibits TNF- $\alpha$ synthesis at m-RNA level (Table1).

Significant decrease in concentration of NF- $\kappa B$ was observed in striatum after treatment with mangiferin as it is a specific inhibitor of NF- $\kappa \mathrm{B}$. This decrease in NF- $\kappa \mathrm{B}$ activation significantly reduces neuro-inflammation as $\mathrm{NF}-\kappa \mathrm{B}$ is considered as 'master regulator' of inflammation. After activation, NF- $\mathrm{KB}$ promotes activation of Toll like receptors 4 (TLR4) which in turn promote NF- $\mathrm{BB}$ activation thus promoting nefarious cycle of inflammation. Mangiferin stops this cycle of inflammation by inhibiting NF-kB activation.

Balance between Th1/Th2 cytokines plays crucial role in inflammation. GATA 3 and T-bet control the Th1/Th2 differentiation. GATA-3 is regulator of Th2 while T-BET regulates the Th1expression. Increased expression of NF- $\mathrm{BB}$ promoted the GATA-3 mRNA and thereby increases the protein expression of GATA-3, while inhibiting the T-bet expression. This causes an imbalance between GATA-3 and T-bet which then results in Th1/Th2 imbalance nad increased expression of Th2 cytokine. Treatment with Mangiferin restores the imbalance between Th1/Th2 cytokine [53], [54] 
Significant increase in activity of caspase-3 and caspase-9 was observed in 6-OHDA lesioned rats which indicate programmed death of dopaminergic neurons. Induction of p53 causes an activation of NF- $\kappa B$ that correlates with the ability of p53 to induce apoptosis. Inhibition or loss of NF- $\kappa \mathrm{B}$ activity abrogated p53-induced apoptosis, indicating that NF- $\kappa \mathrm{B}$ is essential in p53-mediated cell death. Activation of NF- $\mathrm{BB}$ by p53 was distinct from that mediated by tumour-necrosis factor-alpha and involved MEK1 and the activation of pp90rsk [55]. Treatment with mangiferin significantly reduces caspase- 3 and caspase- 9 activity due to its property of inhibiting pro-apoptotic transcription factor NF- $\kappa \mathrm{B}$ and promotes TGF- $\beta$ activity which has anti-inflammatory and proliferative activity [56]. Treatment with levodopa has no significant effect on caspase-3 and caspase-9 activity. Probably, this is the reason why disease progression goes unchecked after treatment with levodopa [25],[57] .

\section{Conclusion}

The findings of this research indicate that mangiferin has a dose-dependent protective effect in 6-OHDA-lesioned rats. Mangiferin efficacy is amplified when combined with levodopa 10 $\mathrm{mg} / \mathrm{kg}$, which is the cornerstone of anti-parkinsonism treatment. Thus, we may conclude that the combination of mangiferin with levodopa may have therapeutic benefit in Parkinson's disease therapy on our results.

Ethics Approval

Before starting the study, necessary approval from the Institutional Animal Ethics Committee (IAEC) of King George's Medical University (KGMU), Lucknow was obtained with approval letter No. 84/IAEC/Pharma/2017.

\section{Consent to Participate: N/A}

Human Rights

This manuscript does not contain any studies on human volunteers or human tissue samples.

Animal Rights

All experiments were done according to the guidelines of the Institutional Animal Ethics Committee of KGMU and the Prevention of Cruelty to Animals Act 1960 of the Government of India.

Availability of Data and Materials 
The authors confirm that the data supporting the findings of this study are available within the manuscript.

Funding

Authors acknowledge Senior Research Fellowship provided to Mr. Prafulla Chandra Tiwari by Indian Council of Medical Research with file no. 45/34-2014/PHA-BMS.

Conflict of Interest

Authors declare that they have no conflict of interest.

\section{Authorship Contribution Statement:}

Pal Rishi and Tiwari PC conceived the experiments

Tiwari PC carried out experiments with assistance from Jain M and Kartik Shipra

Tiwari PC wrote the manuscript and Pal Rishi supervised the manuscript.

All authors provided critical feedback and helped shape the research, analysis and manuscript. 


\section{References:}

1. Moore DJ, West AB, Dawson VL, Dawson TM: Molecular pathophysiology of Parkinson's disease. Annual review of neuroscience 2005, 28:57-87.

2. McGeer PL, McGeer EG: Glial reactions in Parkinson's disease. Movement disorders : official journal of the Movement Disorder Society 2008, 23:474-483.

3. Pal R, Tiwari PC, Nath R, Pant KK: Role of neuroinflammation and latent transcription factors in pathogenesis of Parkinson's disease. Neurological Research 2016, 38:1111-1122.

4. Tiwari PC, Pal R: The potential role of neuroinflammation and transcription factors in Parkinson disease. Dialogues in clinical neuroscience 2017, 19:71-80.

5. Maetzler W, Apel A, Langkamp M, Deuschle C, Dilger SS, Stirnkorb JG, Schulte C, Schleicher E, Gasser T, Berg D: Comparable Autoantibody Serum Levels against Amyloid- and Inflammation-Associated Proteins in Parkinson's Disease Patients and Controls. PloS one 2014, 9:e88604.

6. Barcia C, Ros CM, Annese V, Carrillo-de Sauvage MA, Ros-Bernal F, Gómez A, Yuste JE, Campuzano CM, de Pablos V, Fernandez-Villalba E, Herrero MT: ROCK/Cdc42-mediated microglial motility and gliapse formation lead to phagocytosis of degenerating dopaminergic neurons in vivo. Scientific reports 2012, 2:809.

7. Barcia C, Sánchez Bahillo A, Fernández-Villalba E, Bautista V, Poza YPM, Fernández-Barreiro A, Hirsch EC, Herrero MT: Evidence of active microglia in substantia nigra pars compacta of parkinsonian monkeys 1 year after MPTP exposure. Glia 2004, 46:402-409.

8. Jackson-Lewis V, Smeyne RJ: MPTP and SNpc DA neuronal vulnerability: role of dopamine, superoxide and nitric oxide in neurotoxicity. Minireview. Neurotoxicity research 2005, 7:193-202.

9. Block ML, Zecca L, Hong JS: Microglia-mediated neurotoxicity: uncovering the molecular mechanisms. Nat Rev Neurosci 2007, 8:57-69.

10. Mogi M, Harada M, Kondo T, Riederer P, Inagaki H, Minami M, Nagatsu T: Interleukin-1 beta, interleukin-6, epidermal growth factor and transforming growth factor-alpha are elevated in the brain from parkinsonian patients. Neuroscience letters 1994, 180:147-150.

11. Nagatsu T, Mogi M, Ichinose $H$, Togari A: Changes in cytokines and neurotrophins in Parkinson's disease. Journal of neural transmission Supplementum 2000:277-290.

12. Bessler H, Djaldetti R, Salman H, Bergman M, Djaldetti M: IL-1 beta, IL-2, IL-6 and TNF-alpha production by peripheral blood mononuclear cells from patients with Parkinson's disease. Biomedicine \& pharmacotherapy = Biomedecine \& pharmacotherapie 1999, 53:141-145.

13. Hunot $S$, Boissière F, Faucheux B, Brugg B, Mouatt-Prigent A, Agid Y, Hirsch EC: Nitric oxide synthase and neuronal vulnerability in Parkinson's disease. Neuroscience 1996, 72:355-363.

14. Członkowska A, Kohutnicka M, Kurkowska-Jastrzebska I, Członkowski A: Microglial reaction in MPTP (1-methyl-4-phenyl-1,2,3,6-tetrahydropyridine) induced Parkinson's disease mice model. Neurodegeneration : a journal for neurodegenerative disorders, neuroprotection, and neuroregeneration 1996, 5:137-143.

15. Wu DC, Jackson-Lewis V, Vila M, Tieu K, Teismann P, Vadseth C, Choi DK, Ischiropoulos H, Przedborski S: Blockade of microglial activation is neuroprotective in the 1-methyl-4phenyl-1,2,3,6-tetrahydropyridine mouse model of Parkinson disease. The Journal of neuroscience : the official journal of the Society for Neuroscience 2002, 22:1763-1771.

16. Kim WG, Mohney RP, Wilson B, Jeohn GH, Liu B, Hong JS: Regional difference in susceptibility to lipopolysaccharide-induced neurotoxicity in the rat brain: role of microglia. The Journal of neuroscience : the official journal of the Society for Neuroscience 2000, 20:6309-6316.

17. Fujiwara N, Kobayashi K: Macrophages in inflammation. Current drug targets Inflammation and allergy 2005, 4:281-286. 
18. Giam M, Huang DCS, Bouillet P: BH3-only proteins and their roles in programmed cell death. Oncogene 2008, 27:S128-S136.

19. Becatti M, Prignano F, Fiorillo C, Pescitelli L, Nassi P, Lotti T, Taddei N: The involvement of Smac/DIABLO, p53, NF-kB, and MAPK pathways in apoptosis of keratinocytes from perilesional vitiligo skin: Protective effects of curcumin and capsaicin. Antioxidants \& redox signaling 2010, 13:1309-1321.

20. Aggarwal BB: Nuclear factor-kappaB: the enemy within. Cancer cell 2004, 6:203-208.

21. Pal R, Tiwari PC: Transcription Factor as Therapeutic Targets for Neurodegenerative Disorders: An Update. Modern Approaches in Drug Designing 2018, 1:1-6.

22. Ahn KS, Aggarwal BB: Transcription factor NF-kappaB: a sensor for smoke and stress signals. Annals of the New York Academy of Sciences 2005, 1056:218-233.

23. Bales KR, Du Y, Dodel RC, Yan GM, Hamilton-Byrd E, Paul SM: The NF-kappaB/Rel family of proteins mediates Abeta-induced neurotoxicity and glial activation. Brain research Molecular brain research 1998, 57:63-72.

24. Emmanouil M, Taoufik E, Tseveleki V, Vamvakas SS, Probert L: A role for neuronal NFkappaB in suppressing neuroinflammation and promoting neuroprotection in the CNS. Advances in experimental medicine and biology 2011, 691:575-581.

25. Liu F, Bardhan K, Yang D, Thangaraju M, Ganapathy V, Waller JL, Liles GB, Lee JR, Liu K: NFkappaB directly regulates Fas transcription to modulate Fas-mediated apoptosis and tumor suppression. The Journal of biological chemistry 2012, 287:25530-25540.

26. Mei Y, Zhang Y, Yamamoto K, Xie W, Mak TW, You H: FOXO3a-dependent regulation of Pink1 (Park6) mediates survival signaling in response to cytokine deprivation. Proceedings of the National Academy of Sciences of the United States of America 2009, 106:5153-5158.

27. Pizzi M, Goffi F, Boroni F, Benarese M, Perkins SE, Liou HC, Spano P: Opposing roles for NFkappa B/Rel factors p65 and c-Rel in the modulation of neuron survival elicited by glutamate and interleukin-1beta. The Journal of biological chemistry 2002, 277:2071720723.

28. Ryan KM, Ernst MK, Rice NR, Vousden KH: Role of NF-KB in p53-mediated programmed cell death. Nature 2000, 404:892.

29. Sierra A, Abiega O, Shahraz A, Neumann H: Janus-faced microglia: beneficial and detrimental consequences of microglial phagocytosis. Frontiers in cellular neuroscience 2013, 7:6.

30. BEINKE S, LEY Steven C: Functions of NF-KB1 and NF-KB2 in immune cell biology. Biochemical Journal 2004, 382:393-409.

31. Torres J, Enríquez-de-Salamanca A, Fernández I, Rodríguez-Ares MT, Quadrado MJ, Murta J, Benítez del Castillo JM, Stern ME, Calonge M: Activation of MAPK Signaling Pathway and NF-KB Activation in Pterygium and Ipsilateral Pterygium-Free Conjunctival Specimens. Investigative ophthalmology \& visual science 2011, 52:5842-5852.

32. Xiao K, Liu C, Tu Z, Xu Q, Chen S, Zhang Y, Wang X, Zhang J, Hu C-AA, Liu Y: Activation of the NF-KB and MAPK Signaling Pathways Contributes to the Inflammatory Responses, but Not Cell Injury, in IPEC-1 Cells Challenged with Hydrogen Peroxide. Oxidative medicine and cellular longevity 2020, 2020:5803639.

33. Pal R, Chaudhary MJ, Tiwari PC, Nath R, Pant KK: Pharmacological and biochemical studies on protective effects of mangiferin and its interaction with nitric oxide (NO) modulators in adjuvant-induced changes in arthritic parameters, inflammatory, and oxidative biomarkers in rats. Inflammopharmacology 2019, 27:291-299.

34. Dou W, Zhang J, Ren G, Ding L, Sun A, Deng C, Wu X, Wei X, Mani S, Wang Z: Mangiferin attenuates the symptoms of dextran sulfate sodium-induced colitis in mice via NF-kappaB and MAPK signaling inactivation. International immunopharmacology 2014, 23:170-178. 
35. Sarkar A, Sreenivasan Y, Ramesh GT, Manna SK: beta-D-Glucoside suppresses tumor necrosis factor-induced activation of nuclear transcription factor kappaB but potentiates apoptosis. The Journal of biological chemistry 2004, 279:33768-33781.

36. Ahmad A, Padhye S, Sarkar FH: Role of Novel Nutraceuticals Garcinol, Plumbagin and Mangiferin in the Prevention and Therapy of Human Malignancies: Mechanisms of Anticancer Activity. In Nutraceuticals and Cancer. Edited by Sarkar FH. Dordrecht: Springer Netherlands; 2012: 179-199

37. du Plessis-Stoman D, du Preez J, van de Venter M: Combination treatment with oxaliplatin and mangiferin causes increased apoptosis and downregulation of NFkappaB in cancer cell lines. African journal of traditional, complementary, and alternative medicines : AJTCAM 2011, 8:177-184.

38. Leiro J, Arranz JA, Yanez M, Ubeira FM, Sanmartin ML, Orallo F: Expression profiles of genes involved in the mouse nuclear factor-kappa $B$ signal transduction pathway are modulated by mangiferin. International immunopharmacology 2004, 4:763-778.

39. Paxinos G, Watson C: The Rat Brain in Stereotaxic Coordinates. In 123Library. 6 edition: Academic Press; 2007

40. Schaar KL, Brenneman MM, Savitz SI: Functional assessments in the rodent stroke model. Experimental \& Translational Stroke Medicine 2010, 2:13-13.

41. Cook L, Weidley E: Behavioral effects of some psychopharmacological agents. Annals of the New York Academy of Sciences 1957, 66:740-752.

42. Olsson M, Nikkhah G, Bentlage $C$, Bjorklund A: Forelimb akinesia in the rat Parkinson model: differential effects of dopamine agonists and nigral transplants as assessed by a new stepping test. The Journal of Neuroscience 1995, 15:3863.

43. Ohkawa $\mathrm{H}$, Ohishi $\mathrm{N}$, Yagi K: Assay for lipid peroxides in animal tissues by thiobarbituric acid reaction. Analytical biochemistry 1979, 95:351-358.

44. Lowry OH, Rosebrough NJ, Farr AL, Randall RJ: Protein measurement with the Folin phenol reagent. The Journal of biological chemistry 1951, 193:265-275.

45. Frank. B, M. HL, J. PW, F. WR, V. LE, Z. FG, M. SH, K. CR, E. GD: Polymorphonuclear leukocyte infiltration into cerebral focal ischemic tissue: Myeloperoxidase activity assay and histologic verification. Journal of Neuroscience Research 1991, 29:336-345.

46. Marklund S.; Marklund G: Involvement of the Superoxide Anion Radical in the Autoxidation of Pyrogallol and a Convenient Assay for Superoxide Dismutase. Eur J Biochem 1974, 47:469-474.

47. Sinha AK: Colorimetric assay of catalase. Analytical biochemistry 1972, 47:389-394.

48. Aebi H: Catalase in vitro. Methods in enzymology 1984, 105:121-126.

49. Benzie IF, Strain JJ: Ferric reducing/antioxidant power assay: direct measure of total antioxidant activity of biological fluids and modified version for simultaneous measurement of total antioxidant power and ascorbic acid concentration. Methods in enzymology 1999, 299:15-27.

50. Melamed E, Offen D, Shirvan A, Djaldetti R, Barzilai A, Ziv I: Levodopa toxicity and apoptosis. Annals of neurology 1998, 44:S149-154.

51. Group TPS: Levodopa and the Progression of Parkinson's Disease. New England Journal of Medicine 2004, 351:2498-2508.

52. Bajpai VK, Alam MB, Quan KT, Kwon K-R, Ju M-K, Choi H-J, Lee JS, Yoon J-I, Majumder R, Rather IA, et al: Antioxidant efficacy and the upregulation of Nrf2-mediated HO-1 expression by (+)-lariciresinol, a lignan isolated from Rubia philippinensis, through the activation of p38. Scientific reports 2017, 7:46035.

53. Chang X, Zhu A, Liu F, Zou L, Su L, Li S, Sun Y: Role of NF-kB activation and Th1/Th2 imbalance in pulmonary toxicity induced by nano NiO. Environmental toxicology 2017, 32:1354-1362. 
54. Zhao F, Qu J, Wang W, Li S, Xu S: The imbalance of Th1/Th2 triggers an inflammatory response in chicken spleens after ammonia exposure. Poultry Science 2020, 99:3817-3822.

55. Ryan KM, Ernst MK, Rice NR, Vousden KH: Role of NF-kappaB in p53-mediated programmed cell death. Nature 2000, 404:892-897.

56. Pal PB, Sinha K, Sil PC: Mangiferin attenuates diabetic nephropathy by inhibiting oxidative stress mediated signaling cascade, TNFalpha related and mitochondrial dependent apoptotic pathways in streptozotocin-induced diabetic rats. PloS one 2014, 9:e107220.

57. Wu H, Lozano G: NF-kappa B activation of p53. A potential mechanism for suppressing cell growth in response to stress. The Journal of biological chemistry 1994, 269:20067-20074. 